\title{
Evaluation of the Correlation Between Breast Artery Calcification and Coronary Artery Calcium Scores in Predicting the Risk for Cardiovascular Disease
}

\author{
(1) Ișıl Yurdaıșık¹, (1) Fuad Nurili² \\ ${ }^{1}$ Clinic of Radiology, İstinye University Medical Park Gaziosmanpașa Hospital, İstanbul, Turkey \\ 2Department of Radiology and Interventional Radiology, Memorial Sloan Kettering Cancer Center, Avenue, New York, USA
}

\begin{abstract}
Aim: Coronary artery calcium (CAC) score is a scoring system used in the stratification of coronary risks. Breast artery calcification (BAC) is a type of medial artery calcification that can be visualized using mammography and is also known as arteriosclerosis. It has been reported that a significant correlation exists between BAC and CAC and that the presence of BAC improves the ability of detecting women with CAC. This study aimed to evaluate the relationship between mammographically-detected BAC and CAC.

Materials and Methods: A total of 31 patients who presented to our hospital for diagnostic or screening mammography and who underwent CAC scoring between 2015 and 2018 were included in the study. Agatston method was used to determine the CAC score. Total BAC, which varies from 0 to 12, was measured based on the number and length of calcified vessels and the severity of mammographically-visualized calcification.

Results: The mean BAC scores were found to be 0 in 1 patient, 1-3 in nine patients and 4-12 in 21 patients. The mean CAC scores were found to be 0 in eight patients, 11-100 in 12 patients, 101-400 in eight patients and >400 in three patients. There was a statistically significant positive correlation between the BAC and CAC scores.

Conclusion: This study revealed a positive correlation between the BAC and CAC scores. It was found that mammographic calcification scoring, which is already commonly used as a screening tool and is more advantageous than tomography, can be used for the early determination of intermediate risk groups for cardiovascular diseases.
\end{abstract}

Keywords: Breast artery calcification, coronary artery calcium score, mammography, cardiovascular disease, screening

\section{Introduction}

Cardiovascular diseases (CVDs) are the leading cause of death worldwide with approximately 17.9 persons died from CVD in 2016 (1). Similarly, in our country also CVDs rank first among the causes of death. According to the data of the Turkish Statistical Institute, deaths due to CVDs are the leading among all causes of death by $39.8 \%$ (2). In the Western countries, yearly rate of CVD mortality has been reported as 2-8/1000 in men and 0.6$3 / 1000$ in women aged between 45 and 74 years. In our country, this rate has been reported as 7.6/1000 in men and 3.8/1000 in women in the same age group (3). Identification of asymptomatic persons who are at a higher risk for future cardiovascular events is the basis of implementing preventive strategies. Coronary artery calcium (CAC), score which is a scoring system based on the measurement of the amount of calcium in the arterial walls that supply heart muscle is used for the stratification of cardiovascular risk. Several studies have shown that CAC score is significantly associated with major cardiovascular events (all causes mortality, cardiac mortality, and nonfatal myocardial infarction) in middle and long term follow up (4). However, currently CAC score is not used in routine screening. The use of CAC is based on clinical findings and a history of genetic predisposition. Nevertheless, CAC occurs in the intima of the vessels, and is closely associated 
with aterosclerotic plaque burden. Therefore, the presence of CAC is in fact a diagnostic factor for cardiovascular disease (5).

Breast cancer is the most common type of cancer in women in the developed and developing countries, and is among the most important global healthcare problems (6). It ranks second following lung cancer worldwide (7), accounting for nearly $30 \%$ of all cancers seen in women (8). On the other hand, it is stated that the chance for healing is high when breast cancer is recognized in an early period.

Breast Cancer Screening Program National Standards prepared by the Ministry of Health Public Health Institution recommend screening every 2 years with mammography in women aged between 40 and 69 years (9). Breast Cancer Screening Guidelines by the Turkish Radiology Association accept the age of starting mammographic screening as 40 years, and recommend yearly follow up (10). According to these guidelines, it is advisable to discontinue screening between 70 and 74 years old if life expectancy is under 5 years depending on the age and presence of other comorbidities.

Breast artery calcification (BAC) is a type of medial artery calcification, which can be seen on mammography, and is also named as arteriosclerosis that is known as Monckeberg arteriosclerosis $(11,12)$. Recently, BAC has been shown to be a potential women specific risk factor for both coronary artery disease and cardiovascular disease (13). However, unfortunately the presence or absence of BAC is often neglected in mammographic evaluation. Studies have shown that subclinical atherosclerosis and cardiovascular disease can be assessed with mammography $(14,15)$. It has been reported that there is a significant relationship between BAC and CAC, and the presence of BAC improves the ability for detection of women with CAC (16).

Mammography provides an important alternative screening technique to determine the risk of coronary artery disease in women. Given that millions of women over 40 years old have mammography, a significant correlation between BAC and CVD will provide improvement in risk stratification without additional costs and radiation exposure (17). The objective of this study was to evaluate the relationship between BACs on mammography and CAC score.

\section{Materials and Methods}

Among the women who presented to our hospital for screening or diagnosis with mammographic evaluation, a total of 31 women aged between 40-74 years who recently presented for coronary calcium scoring between October 2015 and June 2018 were included in this study. Women aged under or over the specified age range, those with a history of stroke, transient ischemic or coronary artery disease, patients with coronary stents, advanced coronary calcification, those undergone breast surgery, and patients with chronic inflammatory diseases such as infection or autoimmune diseases, hepatic and/or renal failure were excluded from the study. All BAC and CAC evaluations were performed by a radiologist specialized on this topic.

Before the beginning of the study, the necessary approval was received from the local ethics committee with 2/2019.K018 numbered decision. Patients included in the study were informed about the objective of the study and given written and verbal consents. The study was conducted in accordance with the principles of the Declaration of Helsinki.

\section{Coronary Artery Calcium Scoring}

CAC is a pathognomonic finding of atherosclerosis (18). CAC may be observed in any stage of atherosclerosis. Therefore, determination of CAC level is not only a measurement of calcified plaque burden, but it is also an indicator of the non-calcified plaque burden of the existing atherosclerotic disease. The most common method in the measurement of CAC is Agatston score. This score was described by Agatston et al. (19) in 1990 as the first practically applicable quantitative CAC protocol. In this method, any structure with a density of $130 \mathrm{HU}$ or higher and an area of $1 \mathrm{~mm}^{2}$ or higher is considered as a calcified focus, and the foci found in the anatomic regions of coronary arteries as calcified plaques. Each calcified focus is scored between 1-4 points based on the peak density. Total Agatston score of each person is calculated with summation of the scores of each focus (Table 1).

Coronary artery calcium examinations were performed with visualization between tracheal bifurcation and heart vessel at early mid-diastole, using a 120-sections computed tomography device (Siemens Somatom 2015).

\begin{tabular}{|l|l|l|l|}
\hline \multicolumn{3}{|l|}{ Table 1. Risk stratification according to Agatston score } \\
\hline $\begin{array}{l}\text { CAC } \\
\text { score }\end{array}$ & $\begin{array}{l}\text { Plaque } \\
\text { burden }\end{array}$ & $\begin{array}{l}\text { Cardiovascular } \\
\text { risk }\end{array}$ & $\begin{array}{l}\text { Likelihood of } \\
\text { obstructive disease }\end{array}$ \\
\hline 0 & $\begin{array}{l}\text { No detectable } \\
\text { plaque }\end{array}$ & Very low & Very low $<5 \%$ \\
\hline $1-10$ & $\begin{array}{l}\text { Minimal } \\
\text { plaque }\end{array}$ & Low & Low $<10 \%$ \\
\hline $11-100$ & Mild plaque & Moderate & Mild stenosis \\
\hline $101-400$ & $\begin{array}{l}\text { Moderate } \\
\text { plaque }\end{array}$ & Moderate-to-high & $\begin{array}{l}\text { Likelihood of both } \\
\text { non-obstructive and } \\
\text { obstructive disease }\end{array}$ \\
\hline$>400$ & $\begin{array}{l}\text { Diffuse } \\
\text { atherosclerotic } \\
\text { plaque }\end{array}$ & High & $\begin{array}{l}\text { Likelihood of at } \\
\text { least one significant } \\
\text { stenosis }(\geq 90 \%)\end{array}$ \\
\hline CAC: Coronary artery calcium & \\
\hline
\end{tabular}




\section{Breast Artery Calcification}

Arterial calcification in the breast is a type of medial calcification, which can be easily detected on mammography, and is seen as parallel lines and railways on mammography. Calcification of the arterial intima is considered as coronary calcification and is usually accompanied by plaques consisting of lipid deposits. Whereas BAC occurs in the middle layer of the artery, and known as Mönckeberg medial calcific sclerosis. BAC is a novel potential risk stratification tool for CVD.

Total BAC score differs between 0-12 points, and is produced based on three elements on mammography: the number of calcified vessels (0-6 points), the severity of artery calcification (0-3 points) and the length of calcified vessels (0-3 points). Accordingly, the total scores are divided into three categories with 0 point indicates the absence of BAC, 1-3 points mild calcification, and 4-12 points significant calcifications (Table 2).

Mammography was performed by acquiring mediolateral oblique and craniocaudal images including tomosynthesis (Siemens Mammomat Inspiration 2015).

\section{Statistical Analysis}

Data obtained in the study were analysed using SPSS Version 20.0 (SPSS 20.0 for Windows IBM, Virginia, USA) statistical software. Normality of the data was tested and normal distribution value

\begin{tabular}{|l|l|l|l|l|l|}
\hline \multicolumn{2}{|l|}{ Table 2. BAC scoring system } \\
\hline $\begin{array}{l}\text { Number of } \\
\text { vessels }\end{array}$ & \multicolumn{2}{l|}{ Length of vessels } & \multicolumn{2}{l|}{ Severity of calcification } \\
\hline 1 & 1 & $1 / 3$ involvement & 1 & Spot calcification & 1 \\
\hline 2 & 2 & $\begin{array}{l}1 / 3-2 / 3 \\
\text { involvement }\end{array}$ & 2 & $\begin{array}{l}\text { Spot calcification in } \\
\text { the lumen }\end{array}$ & 2 \\
\hline 3 & 3 & $\begin{array}{l}>2 / 3 \\
\text { involvement }\end{array}$ & 3 & $\begin{array}{l}\text { Intense calcification } \\
\text { in the vessel } \\
\text { including tangential } \\
\text { walls and lumen }\end{array}$ & 3 \\
\hline \multicolumn{3}{|l|}{ BAC: Breast artery calcification } \\
\hline
\end{tabular}

\begin{tabular}{|c|c|c|c|c|c|}
\hline & $\begin{array}{l}\text { No } \\
\text { BAC }\end{array}$ & $\begin{array}{l}\text { Mild } \\
\text { calcification }\end{array}$ & $\begin{array}{l}\text { Significant } \\
\text { calcification }\end{array}$ & Total & $\begin{array}{l}p \\
\text { value }\end{array}$ \\
\hline No CAC & 1 & 7 & - & 8 & \multirow{6}{*}{0.001} \\
\hline Minimal plaque & - & - & - & - & \\
\hline Mild plaque & - & 2 & 10 & 12 & \\
\hline $\begin{array}{l}\text { Moderate } \\
\text { plaque }\end{array}$ & - & - & 8 & 8 & \\
\hline $\begin{array}{l}\text { Diffuse } \\
\text { atherosclerotic } \\
\text { plaque }\end{array}$ & - & - & 3 & 3 & \\
\hline Total & 1 & 9 & 21 & 31 & \\
\hline
\end{tabular}

was calculated with Skewness-Kurtosis test. Continuous numerical variables are expressed median (minimum-maximum) values as appropriate, and categorical variables as percentage (\%). Paired Student's t-test was used in the comparison of continuous variables. The correlation between continuous variables was studied with Pearson's correlation analysis. $\mathrm{P}<0.05$ values were considered statistically significant.

\section{Results}

A total of 31 women were included in the study. The median age of the participants was 57 (40-74) years. BAC scores were found as 0 in one (3.2\%) patient, 1-3 in nine (29.0\%) patients, and 4-12 (67.7\%) in 21 patients. Both BAC and CAC scores were increased as the age of the patients increased.

CAC scores were found as 0 in eight (25.8\%) patients, 11-100 in 12 (38.7\%) patients, 101-400 in eight (25.8\%) patients and $>400$ in three $(9.2 \%)$ patients. Sample of the study mostly consisted of the patients with a CAC score between 11-100 and a BAC score between 4-12.

CAC score was 0 in a patient with a BAC score of 0 , while seven (77.8\%) of patients with BAC scores of 1-3 were in CAC 0 group, and the remaining two patients were in CAC 11-100 group. Of the 21 patients in BAC 4-12 group, 10 (47.6\%) were in CAC 11-100 group, eight (38.1\%) in CAC 101-400 group and 3 (9.68\%) in CAC $>400$ group. Accordingly, the highest rate of patients was found in BAC 4-12 and CAC 11-100 groups by $47.6 \%$ (Chart 1).

When the results of t-test and mean values of the groups were evaluated together, CAC scores were found to be more effective. Effect of BAC scores on CAC scores was found as $63 \%$. The correlation between BAC and CAC scores was statistically significant $(r=0.796 p<0.005)$ (Table 3). When cardiovascular risk factors related to BAC were examined; Diabetes mellitus was found in 19 (61.29\%), hypertension in 17 (54.83\%), hyperlipidemia
Distribution of CAC scores

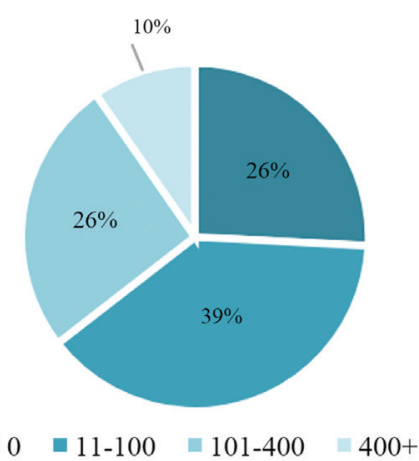

\section{Distribution of BAC scores}

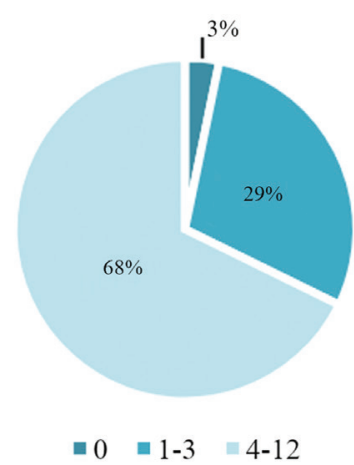

Chart 1. Distribution of $C A C$ and $B A C$ scores

BAC: Breast artery calcification, CAC: Coronary artery calcification 
in 16 (51.61\%), smoking in four (12.90\%), chronic kidney disease in two (6.45\%) patients and family history in one (3.22\%) patient. The relationship between the presence of BAC and cardiovascular risk factors was given in Table 4 .

Samples of moderate and moderate-advanced stage coronary artery and breast vascular calcifications are given in Figures 1 and 2 .

\section{Discussion}

CAC scoring has been a risk estimation tool for coronary artery calcification as an indicator of subclinical heart disease (19). Higher CAC scores are associated with a higher risk of coronary events. In addition, the presence of CAC has been used to justify modification treatments with a more aggressive CAD risk factor such as aspirin, statins and lifestyle changes (20). Studies have shown that the extent of CAC is strongly associated with the rate of future cardiac events, and that high prevalence of CAC in patients with coronary heart disease make percutaneous coronary intervention difficult (4).

Table 4. Relationships between the presence of BAC and cardiovascular risk factors

\begin{tabular}{|l|l|l|}
\hline \multirow{2}{*}{} & \multicolumn{2}{|c|}{ BAC scores } \\
\cline { 2 - 3 } & BAC - & BAC + \\
\hline Number of patients (n) & 1 & 30 \\
\hline Age at mammography (mean \pm SD) & $54(7.5)$ & $59(8)$ \\
\hline Presence of BAC & 1 & 30 \\
\hline Diabetes mellitus & 12 & 19 \\
\hline Hypertension & 14 & 17 \\
\hline Smoking & 4 & 4 \\
\hline Hyperlipidemia & 15 & 16 \\
\hline Chronic kidney disease & 0 & 2 \\
\hline Family history & 0 & 1 \\
\hline BAC: Brest atery cacifctin, SD: Stand & \\
\hline
\end{tabular}

BAC: Breast artery calcification, SD: Standard deviation

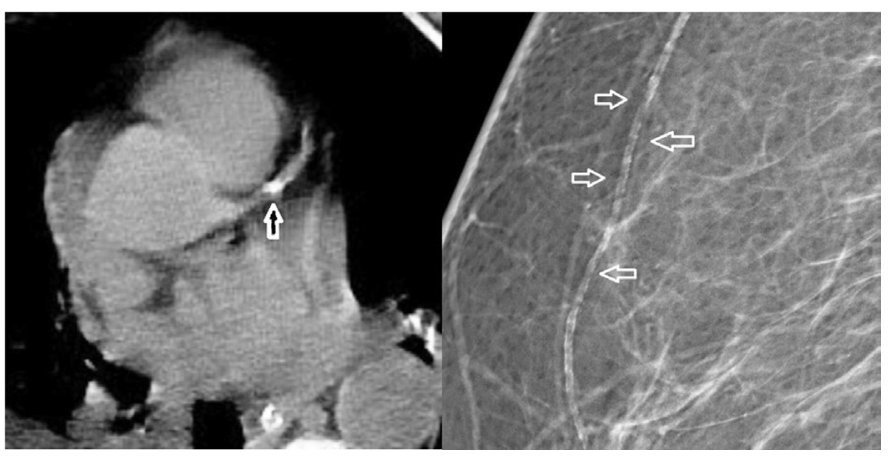

Figure 1. Mild calcification in the left anterior descending coronary artery of a 56-year-old woman with BAC score 4

BAC: Breast artery calcification

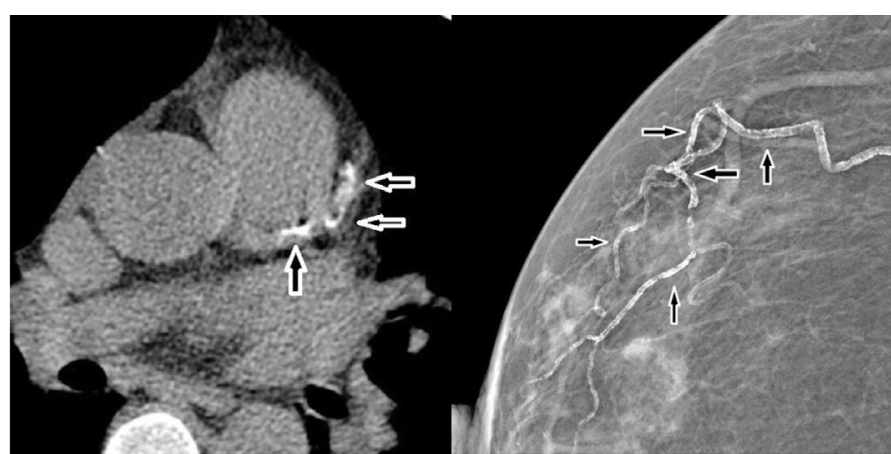

Figure 2. Moderate calcification in the left anterior descending coronary artery of a 74-year-old woman with BAC score 9

BAC: Breast artery calcification

Mammography screening has been widely used in early detection of breast cancer. BAC is a benign finding on mammography especially in elderly women. It has been proposed that this incidental finding can be used as an indicator of vascular disease (21). Therefore, relationships between BAC and cardiovascular disease markers and potential risk factors and CAC scores $(22,23)$.

In the present study the relationship between BAC and CAC was evaluated. As a result of the evaluations and analyses, a strong correlation was found between BAC and CAC. In a study by Pecchi et al. (16) in 2003, a strong correlation was found between BAC and CAC. In 2007, Maas et al. (24) reported a strong correlation between BAC and CAC in 499 women at the end of 9-year follow up. More recently, in a retrospective study by Chadashvili et al. (25) with 145 women who were referred for coronary computed tomography within one year after mammography screening; a significant association was found between the presence of $\mathrm{CAC}>11$ and $\mathrm{BAC}$.

$B A C$ rates increase in patients as CAC scores increase. In our study, $B A C$ scores were found in the range of 4-12 in three patients with a CAC score $>400$. In a study by Matsumura et al. (26) in 2013, BAC scores were significantly increased in women with a CAC score $>400$. However, there is currently no exact consensus on this issue in the literature. In a cross-sectional study by Moradi et al. (27), the relationship between BAC and CAC was investigated in 150 Iranian women aged $>40$ years, and no significant correlation could be found. The authors stated that BAC and the presence of significant coronary stenosis might be independently associated with age, and therefore older women were more susceptible for both BAC and CAC. In our study also, both BAC and CAC scores were increased as the age of the patients increased.

Several factors might have affected these contradictory results. Different study designs might be the major factor affecting the differences between these results. The effect of cardiac risk factors on coronary arteries should be kept in mind. 
In a study by Wendling (28) in 2016, CAC was found by $47.6 \%$ among 292 women. The authors reported a significant correlation between CAC and BAC. In our study, moderate cardiovascular risk was found by $47.6 \%$ among the participants. In addition, we found a strong correlation between CAC and the elements of BAC (number of calcified vessels, length of calcified vessels, and severity of calcification). In a study by Fathala et al. (29), similar results were reported. In addition, in another prospective study by Dale et al. (30) including 1000 women, the likelihood of CAC was found as 6.2 times higher in women with BAC compared to those without BAC in all age groups. The results of that study which has a high number of participants and those of the other studies indicate that mammography could be a helpful tool for the screening of coronary vascular disease. Likewise, previous studies except for the study by Moradi et al. (27), in our study also a significant correlation was found between BAC and CAC scores. However, the reported results should be cautiously interpreted. Because there is difference between sample sizes of the studies, and participants have already presented for computed tomography screening in most of these studies. In addition, different methods and threshold values were used for the measurement of CAC scores among the studies. Sensitivity of $B A C$ in prediction of CAC on mammography is variable and is reported between $17 \%$ and $91 \%$. Again, specificity of BAC score is reported between $54 \%$ and $94 \%$ in different studies. Therefore, further studies with larger cohorts are needed for establishing a definitive consensus on the relationship between these two scores in the literature and introduction of BAC score in routine clinical practice for the prediction of CAC.

\section{Study Limitations}

This study has several limitations. First, the number of patients was relatively small. Second, we included only the women who presented for CAC score evaluation. Finally, the study has no long term follow up data. However, we believe that our results would provide contribution to the future consensus on this issue in the literature.

\section{Conclusion}

We found a positive correlation between BAC and CAC scores in the studied sample. This correlation between BAC and CAC scores could be used as a diagnostic tool in asymptomatic women. Criteria of this diagnostic method could be determined with further studies including a larger series of patients and longer follow-up.

\section{Ethics}

Ethics Committee Approval: Before the beginning of the study, the necessary approval was received from the local ethics committee with 2/2019.K-018 numbered decision.
Informed Consent: Patients included in the study were informed about the objective of the study and given written and verbal consents. The study was conducted in accordance with the principles of the Declaration of Helsinki

Peer-review: Internally and externally peer-reviewed.

\section{Authorship Contributions}

Surgical and Medical Practices: I.Y., Concept: I.Y., Design: F.N., Data Collection or Processing: F.N., Analysis or Interpretation: F.N., Literature Search: F.N., Writing: I.Y.

Conflict of Interest: No conflict of interest was declared by the authors.

Financial Disclosure: The authors declared that this study received no financial support.

\section{References}

1. World Health Organization 2017, cardiovascular disease, viewed 21 January 2019. <https://www.who.int/en/news-room/fact-sheets/detail/ cardiovascular-diseases-(cvds)>

2. TüiK Haber Bülteni, Ankara Sayı:24572, 27 Nisan 2017 http://www.tuik.gov. tr/HbPrint.do?id=24572 (Accessed on: 25/03/2019).

3. TüiK Haber Bülteni, Ankara Sayı:16050, 30 Nisan 2014, http://www.tuik.gov. tr/PreHaberBultenleri.do\%3Fid\%3D16050

4. Greenland P, Bonow RO, Brundage BH, Matthew J Budoff, Mark J Eisenberg, Scott M Grundy, et al. ACCF/AHA 2007 clinical expert consensus document on coronary artery calcium scoring by computed tomography in global cardiovascular risk assessment and in evaluation of patients with chest pain: a report of the American College of Cardiology Foundation Clinical Expert Consensus Task Force (ACCF/AHA Writing Committee to Update the 2000 Expert Consensus Document on Electron Beam Computed Tomography) developed in collaboration with the Society of Atherosclerosis Imaging and Prevention and the Society of Cardiovascular Computed Tomography. J Am Coll Cardiol. 2007;49:378-402.

5. Nasir K, Bittencourt MS, Blaha MJ, Blank-stein R, Agatson AS, Rivera JJ, et al. Implications of Coronary Artery Calcium Testing Among Statin Candidates According to American College of Cardiology/American Heart Association Cholesterol Management Guidelines: MESA (Multi-Ethnic Study of Ath. erosclerosis). Journal of the American College of Cardiology. 2015;66:165768

6. Yiğit A. Mamografi Sağıık Teknolojisi ile Meme Kanseri Tarama Programının Klinik Etkililiğinin Meta Analiz Yöntemiyle Değerlendirilmesi. SBE Dergisi. 2017;28:401-30.https://sbedergi.sdu.edu.tr/assets/uploads/sites/343/ files/28-sayi-yazi22-20112017.pdf

7. Topuz, E. Meme Kanseri. Tanı-Tedavi-Takip. In: Nobel Tıp Kitapevleri, İstanbul, Aydıner A, İ̆ci A, editors, 2006.

8. Aslan FE, Gürkan A. Kadınlarda Meme Kanseri Risk Düzeyi. Meme Sağlığ Dergisi. 2007;3:63-8.

9. Meme Kanseri Tarama Programı Ulusal Standartları. https://hsgm. saglik.gov.tr/tr/kanser-tarama-standartlari/listesi/meme-kanseri-taramaprogram\%C4\%B1-ulusal-standartlar\%C4\%B1.html

10. TRD Yeterlilik Kurulu, Rehber ve Standartlar Komitesi-Meme Kanseri Tarama Rehberi, 2011. https://www.turkrad.org.tr/assets/standartlar/meme-taramarehberi.pdf

11. Everhart JE, Pettitt DJ, Knowler WC, Rose FA, Bennett PH. Medial arterial calcification and its association with mortality and complications of diabetes. Diabetologia. 1988;31:16-23. 
12. Shanahan CM, Cary NR, Salisbury JR, Proudfoot D, Weissberg PL, Edmonds ME. Medial localization of mineralization-regulating proteins in association with Monckeberg's sclerosis: evidence for smooth muscle cell-mediated vascular calcification. Circulation. 1999;100:2168-76.

13. Jiang X, Clark M, Singh RK, Juhn A, Schnatz PF. Association of breast arterial calcification with stroke and angiographically proven coronary artery disease: a metaanalysis. Menopause. 2015;22:136-43.

14. Hendriks EJ, de Jong PA, van der Graaf Y, Mali WP, van der Schouw YT, Beulens JWJ. Breast arterial calcifications: a systematic review and meta-analysis of their determinants and their association with cardiovascular events. Atherosclerosis. 2015;239:11-20.

15. Shah N, Chainani V, Delafontaine P, Abdo A, Lafferty J, Abi Rafeh $\mathrm{N}$. Mammographically detectable breast arterial calcification and atherosclerosis. Cardiol Rev. 2014;22:69-78.

16. Pecchi A, Rossi R, Coppi F, Ligabue G, Modena MG, Romagnoli R. Association of breast arterial calcifications detected by mammography and coronary artery calcifications quantified by multislice CT in a population of postmenopausal women. Radiol Med. 2003;106:305-12.

17. Yoon YE, Kim KM, Han JS, Khang SH, Chun EJ, Ahn S, et al. Prediction of subclinical coronary artery disease with breast arterial calcification and low bone mass in asymptomatic women: Registry for the Women Health Cohort for Breast, Bone, and Coronary Artery Disease Study. Jacc Cardiovasc Imaging. 2018;12:1202-11.

18. Budoff MJ, Gul KM. Expert Review on Coronary Calcium. Vasc Health Risk Manag. 2000;4:315-24.

19. Agatston AS, Janowitz WR, Hildner FJ, Zusmer NR, Viamonte Jr M, Detrano R. Quantification of coronary artery calcium using ultrafast computed tomography. J Am Colle Cardiol. 1990;15:827-32.

20. Taylor AJ, Bindeman J, Feuerstein I, Le T, Bauer K, Byrd C, et al. Communitybased provision of statin and aspirin after the detection of coronary artery calcium within a community-based screening cohort. J Am Coll Cardiol. 2008;51:1337-41.
21. Markopoulos C, Mantas D, Revenas K, Kouskos E, Tzonou A, Liapis C, et al. Breast arterial calcifications as an indicator of systemic vascular disease. Acta Radiol. 2004;45:726-9.

22. Pidal D, Sánchez Vidal MT, Rodríguez JC, Corte MD, Pravia P, Guinea O, et al. Relationship between arterial vascular calcifications seen on screening mammograms and biochemical markers of endothelial injury. Eur J Radiol. 2009;69:87-92.

23. Sedighi N, Radmard AR, Radmehr A, Hashemi P, Hajizadeh A, Taheri AP. Breast arterial calcification and risk of carotid atherosclerosis: focusing on the prefentially affected layer of vessel wall. Eur J Radiol. 2011;79:250-6.

24. Maas AH, van der Schouw YT, Atsma F, Beijerinck D, Deurenberg J, Mali W, et al. Breast arterial calcifications are correlated with subsequent development of coronary artery calcifications, but their aetiology is predominantly different Eur J Radiol. 2007;63:396-400.

25. Chadashvili T, Litmanovich D, Hall F, Slanetz PJ. Do breast arterial calcifications on mammography predict elevated risk of coronary artery disease? Eur J Radiol. 2016;85:1121-4.

26. Matsumura ME, Maksimik C, Martinez MW, Weiss M, Newcomb J, Harris K, et al. Breast artery calcium noted on screening mammography is predictive of high risk coronary calcium in asymptomatic women: a case control study. GefaÃàsskrankheiten J Vas Dis. 2013;42:429-33.

27. Moradi M, Atoosa A, Abedi M. Relationship between breast arterial calcification on mammography with CT Calcium scoring and coronary CT angiography results. Adv Biomed Res. 2014;3:79.

28. Wendling P. Breast Arterial Calcification on Mammography IDs Atherosclerotic CVD Risk. https://www.medscape.com/viewarticle/861029

29. Fathala AL, Alabdulkarim FM, Shoukri M, Alanazic M. Association between breast arterial calcifications found on mammography and coronary artery calcifications in asymptomatic Saudi women. Ann Saudi Med. 2018;38:433-8.

30. Dale PS, Mascarhenas C, Richards M, Mackie G. Mammography as a screening tool for coronary artery disease. J Surg Res. 2008;148:1-6. 